\title{
Effects of Private Speech on Math Problem Solving Performance of Fifth Grade Male Students
}

\author{
Masoud Salimi \\ Department of Psychology, Payame Noor University, Isfahan, Iran
}

\section{Doi:10.5901/mjss.2016.v7n3s3p151}

\begin{abstract}
The aim of current research is to study the effects of private speech on math problem solving performance of fifth grade male students. To this end, fivemale elementary schools were selected from education district 3 in Isfahan, Iran using cluster random sampling method. A test including 12 math problems were given to fifth grade students of selected schools $(n=168)$ and those who used private speech during problem solving were identified $(n=35)$. The average of scores of two groups (with and without private speech) in math tests was compared with T-test. There was no significant difference among two groups $(p>0.05)$.
\end{abstract}

Keywords: Private Speech, Problem Solving, Mathematics Education.

\section{Introduction}

According to Vygotesky's theory regarding developmental relationship between thoughts and language, a basic turn in development is when pre-verbal thoughts and pre-thought language come simultaneously to generate new and basic forms of mental performance (Vygotesky, 1934, 1987; quoted in Fernyhough and Fradley, 2005). Private speech phenomenon (i.e. speech which is not clearly addressed other listener) is regarded as a useful window for psychologists toward this turn in development. In the view of Vygotesky, private speech is a gradual internalization stage.

Research on private speech phenomenon provides an opportunity for experimental testing of Vygotesky's ideas regarding relationship between thoughts and language (Berk, 1992). When the first English translation of Vygotesky's work was done, psychologists raised several questions regarding form and function of children private speech. For example, within private speech development in early preschool years, the authors provided public support for Vygotesky's predictions on age related changes in experience and structure of this form of speech, and it was specified private speech passes a predictable path; from explicit irrelevant task speech to explicitly relevant task speech such as selfregulation statements and finally as external manifestations of internal speech such as whispering, chattering and inaudible whisper (e.g. Berk, 1986; Berk and Garvin, 1984; Bivens and Berk, 1990; Kohlberg, Yager and Hjertholm, 1968; Winsler, Diaz, and Montero, 1997). However, there is limited support for this view of Vygotesky that private speech is preschool years and elementary school has implicit state (underground structure) (Fernyhough and Fradley, 2005). Several studies reported high levels of private speech in early years (e.g. Berk and Garvin, 1984; Berk and Potts, 1991) and adulthood (Duncan and Cheyne, 2002).

It seems that age interferes in the use of private speech. Some studies supported this Vygotesky's view that explicit private speech is reduced by increased age and it is internalized. Bivens and Berk (1990) showed that consistent with Vygotesky's theory, externalized, self-driving, task irrelevant and task relevant private speech of children reduced by increased age. While external manifestations related to internal speck task (such as inaudible speaking and movement of the lips and tongue) increases by age increase. Winsler et al. (1997) in a sample $(n=40)$ of $3-5$ years old children found task related private speech has curve relationship with the age. Winsler and Naglieri (2003) investigated implicit and explicit verbal strategies of problem solving, developmental turns, awareness of used strategies and relationship with performance in task in a large sample of $5-17$ years old children $(n=2,156)$. Children's verbal strategies developed to semi-implicit and totally implicit from explicit with increasing age. Awareness of children about use of verbal strategies was low and it increased by the age. Although verbal strategies were correlated with competencies of younger children, self-talk and task performance were not correlated in children. It shows this strategy considerably turns to a relatively non-effective strategy over the time. Winsler et al. (2003) studied developmental stability and change in children private speech during preschool years. A group of 3 and 4 years old children $(n=32)$, who were normal in terms of development, was observed twice within 6 months with personal problem solving tasks. Indexes related to private speech were collected from recorded video tapes. Developmental changes during preschool years occurred in use of children from 
private speech and its internalization during problem solving. These changes were as reduction on total of social speech expression, reduction in average number of stated words, and increase in internalized private speech. Vygotesky, unlike Piaget who considered private speech as egocentric speech, believed that private speech has several important cognitive functions. He defined private speech as a mechanism that one reaches to self-regulation through communicating with him. Kopecky et al. (2005) wrote that Vygotesky consideredprivate speech as a development plan which initiates external talks which are more similar to social speech in terms of structure and function, and then it proceeds with self-regulation function through verbalization and finally it develops in the form of internal verbalization, i.e. development silence. Berk and Garvin (1984) found children private speech is multifaceted and different and it has different types, each with separate development goals. These different types referred by Berk and Garvin include: 1. Verbal play, 2. Emotional expression, 3. Self-visualization growth, 4. Self-regulation. Self-regulation role of private speech was investigated in some studies. Self-regulation is a process through which one thinks of it and steps toward his goals. Private speech selfregulation functions include designing, reminding, guiding and working on task. Each of these functions paly significant roles in helping causes or accomplishing a task or achieving a special goal. Berk (1986) observed that first and second grade students use private speech to guide their thoughts during solving difficult math problems. $4-6$ years old subjects of Duncan and Pratt (1997) used private speech to designwriting tasks and chain story plans. Matuga (2003/2004) observed first, third and fifth grade subjects used private speech to design strategies before working on tasks.

Logically this question is raised behind Vygotesky's approach: if private speech plays positive role in selfregulation, use of it should be accompanied by better performance in the task. Preliminary studies led to controversial results. Some authors reported positive relationship between private speech and performance $\mathrm{n}$ task.

Berk (1986) observed 75 first to third grade students during answering to a math tests. He found there is strong correlation between specific types of private speech and test results of students. That is, performance of the child can be predicated through paying attention to the type of private speech used by him. Berk also showed younger children academically outperform using more audible (louder) private speech. For older children, Berk found those who were able to internalize their private speech, showed better performance in math tests. Winsler et al. (1997) examined main hypotheses of Vygotesky's theory regarding private speech performance on preschool children. Forty preschool students at age $3-5$ performed a task which required selective attention. Tester assistant warned then if needed. According to authors, considering methodological limitations in previous studies, a more accurate approach was used for analysis of speech - performance relationships based on type of task. Using this approach, possible states in private speech and performance were separated: speech related to task, speech unrelated to task, silence and performance (success, failure). Results indicated: 1. Task related speech was used more in success cases than failure cases, while it was contrary in task unrelated speech, 2. Children were more probable to use private speech following warning of the assistant on successful questions compared to absence of warning, 3. Following warning of the assistant, if children showed self-talk, it was more probable to successfully answer the next question compared to when he was silent. Fernyhough and Fradley (2005) studied relationship between speech and performance and found self-regulation levels of private speech are significantly related to performance in current (simultaneous) task. Winsler, Manfra and Diaz (2007) investigated impacts of children private speech on their performance in task in two groups; one was behaviorally exposed to risk and control group, who performed regular practice- speech (verbal - practical) task. 29 preschool children, who were behaviorally exposed to risk, and 43 children as control group performed two versions of a regular speech - practice (motor chain version and numerical version) in two sessions, one with verbal training and the other without verbal training. Results showed risk exposed children used speech more automatically than control group and showed better performance. Two groups of children showed better performance as they were trained to use speech. Lane and Schooler (2004) reported that undergraduate students who were trained to use private speech during a logical retrieval task were able to retrieve more information from their memory compared to those who were not trained.

Some other research works reported poor or no relationship between private speech and performance in task. Goudena (1987), based on Vygotesky'stheory regarding private speech, tested this hypothesis: children can produce more private speech during solving problem following interaction with a cooperating adult compared to presence of a noncooperating adult with inactive presence during cognitive task implementation. 22 children in ages 4 years and 2 moths to 4 years and 10 months participated in the study. Main research hypotheses were supported, however, no reliable relationship found between generated private speech and performance quality in task. Winsler and Naglieri (2003) on a large sample of 5-17 years old children $(n=2,156)$ showed although verbal strategies were correlated to competencies in younger children, self-talk was not correlated with performance in task for children. Roberts and Tharp (1980) studied private speech in 25 first grade children during an academic task of problem solving. Each child was video recorded twice; once during completing a difficult version and a simple version of task as filling blank sentences and writing them and, once during working with microscope. The motions and related verbal behaviors were coded. Although verbal 
thinking before motor action occurred along with it, overall few self-trainingstrategies were used. Less smart children who were less successful in tasks used self-training strategies as smarter children. The only self-training strategy frequently used by smarter children was audible (aloud) reading, which is directly related to the goal.

Some studies indicate private speech may not influence current performance, but it may influence future performance. For example, Bevens and Berk (1990) found positive correlation between speech and success in task in the future. Frauenglass and Diaz (1985) showed private speech is mostly accompanied by failure in current performance, not with success in task. Application of this finding is that private speech as a strategy which facilitates children's developmental domination over a task is mostly correlated with future successes rather than current successes. The idea which experiences of private speech predicts future performance rather than current performance was supported by some reports. Fernyhough and Fradley (2005) mentioned some studies by Azmita (1992), Behrend, Rosengren and Perlmutter (1992), Bevens and Berk (1990), and Gaskill and Diaz (1991).

Relationship between private speech and difficulty levels of task was considered in some studies. In Vygotesky's theory, adaptive performance of private speech was introduced as a self-regulating tool. Some findings indicate as a task gets more difficult, it is more probable that children show explicit self-guiding speech as a behavioral companion. The main prediction of Vygotesky is that private speech increases with increased difficulty of task. This prediction was supported in studies on children (Beaudichon, 1973; Duncan and Pratt, 1997; KohLberg et al., 1968) and young adults (Duncan and Cheyne, 2002). Berk and Garvin (1984) deeply investigated Vygotesky's theory. They observed private speech patterns in 36 children in 5 to 10 years. Vygotesky believed that basis of private speech is social and when tasks get more difficult, it is increased. Their findings supported this hypothesis. Behrend et al. (1989) observed 24 children at three age levels (2, 3.5 and 5 years old) while working on 3 puzzles with different levels of difficulty in two situations: alone and in presence of a parent. They assumed if private speech has self-regulating nature, it should be systematically a function of child's age, task difficulty, and presence of the other in a task situation, and also it would have positive relationship with performance in task. In this research, speeches of children during problem solving were recorded and coded privately and socially. Their findings showed private speech has curve relationship with difficulty of puzzle. Highest private speech was observed than difficulty level of the task was averagely or partially higher than current ability level of the child. In the study by Fernyhough and Fradley (2005) a mechanical version of Tower of London (TOL) was provide on a sample of 5 and 6 years old children $(n=46)$. Two series of four puzzles with increasing difficulty level were implemented in two situations. A second class relationship was found between private speech and difficulty level of the task. But no evidence on change toward self-regulation was observed in different types of price speech with increasing task difficulty level. Assumption of a linear relationship between private speech and task difficulty is undeniable, but it was proposed that ideas of Vygotesky to be considered mostly as a second class relationship between these variables. It is probable when task is in one's ability range or in the zone of proximal development; private speech occurs more (Behrend et al., 1989). When the task is too simple, private speech has no necessity, because self-regulating processes have already been internalized. When the task is too difficult, private speech would be ineffective (Fernyhough and Fradley, 2005).

Review of studies on impact of private speech use in different tasks especially in problem solving related tasks gives inconsistent results. Some authors reported positive relationship between private speech and performance in task. Some other reported low or lack of relationship between two variables, and some showed private speech affects performance in task in the future rather than in the current time. On the other hand, most studies were conducted on $3-8$ years old children. Thus, performing more studies in this regard and on higher age range groups seems necessary. Decision making regarding encouraging children to use private speech should be done based on the research works. More importantly, importance of mathematics in curriculum, daily life and occupational future of students in one hand, and difficulty of math problem solving for students on the other hand, showed necessity to perform studies to show usefulness of different factors in math problem solving. Current research was conducted aiming at investigating impact of private speech on fifth grade elementary male students in math problem solving. It is clear that findings of the current work would have implications for use of teachers, instructors, and parents.

\section{Methodology}

\subsection{Research Method}

This research was conducted using ex post factor comparative research. 


\subsubsection{Research Population}

Research population includes all fifth grade male students in public elementary schools of district 3 in Isfahan.

\section{Sample and Sampling Method}

Five male elementary schools were selected from education district 3 in Isfahan, Iran using cluster random sampling method. Research sample included all fifth grade male students $(n=168)$. Table 1 gives the number of sample students in terms of schools.

Table 1: number of sample students in terms of schools

\begin{tabular}{|c|c|c|c|c|c|c|}
\hline School & Rezvan & Amirkabir & Imam Sadigh & ShahidFadaee & Hamedanian & Sum \\
\hline Number of Students & 22 & 24 & 34 & 28 & 60 & 168 \\
\hline
\end{tabular}

\subsection{Measurement Tool}

A test for solving verbal math problems was used as measurement tool. for content validity control, firstly a table of lesson characteristics (test plan table) was prepared for about 40 percent of fifth grade math coursebook. Then, based on this table, 16 verbal problems were prepared. Questions were given to two referees (fifth grade teacher) so that they give opinion regarding relevance and suitability of questions. They were working in other schools of district 3 in Isfahan who were not among sample schools. Percent of general agreement of two referees was obtained as 93.75. 1 question was identified as inappropriate and 14 questions were recognized as appropriate by two referees. They had different ideas regarding one question. Both were eliminated and 14 questions agreed by referees were selected for preliminary implementation. In preliminary implementation of the test in a school which was not among sample schools it was found the number of questions for one 50-min test session is high. Thus, two questions with lower Discrimination index were eliminated from test and 12 questions were selected for testing math problem solving. Score of items was specified in consulting with two referees. A correction key with analytical scoring method was prepared for the test so that errors in scoring are minimized in correction. Coefficient of correlation between test scores with first semester's math score of students as mentioned in their report card was 0.72 . Split-half reliability was used to calculate the reliability. The correlation coefficient of the two halves of the test questions (with odd and even) was calculated as 0.84 using Spearman - Brown formula.

\section{Implementation}

Implementing the test lasted 50 min. name of students who used private speech (slow self-talk or lip reading) during problem solving was written. After implementation, papers of students were corrected using pre-specified key using analytical scoring, where score of each part was specified in each question. Means of scores obtained by both groups in math problem solving test were compared with t-test for independent groups.

\section{Results}

Results of comparing average scores of both groups with and without private speech use in soling math problems with ttest for independent groups are given in Table 2.

Table 2: Comparison of average scores of fifth grade male students with and without private speech use in math problem solving

\begin{tabular}{|l|c|c|c|c|c|c|}
\hline Group & No. & average & SD & t Statistics & DF & P \\
\cline { 1 - 6 } With private speech use & 35 & 12.21 & 4.33 & \multirow{2}{*}{0.46} & \multirow{2}{*}{1666} & $\mathrm{P}=0.70$ \\
\hline Without private speech use & 133 & 12.65 & 5.05 & & \\
\hline
\end{tabular}

As observed, difference between averages of two groups is partial and it is not significant statistically. 


\section{Discussion and Conclusion}

Results of this work indicate average scores of two groups of fifth grade male students in math problem solving with and without private speech use show to significant difference. In other words, private speech has no impact on performance of fifth grade male students in solving verbal math problems.

Findings are consistent with findings by Winsler and Naglieri (2003), Frauenglass and Diaz (1985), and Goudena (1987). Also, studies by Azmita (1992), Behrend et al. (1992), Bevens and Berk (1990), and Gaskill and Diaz (1991) (quoted in Fernyhough and Fradley, 2005) showed experiences of private speech influence success in task in the future rather than in current performance. However, these findings are inconsistent with findings by Berk (1986), Winsler et al. (1997), Fernyhough and Fradley (2005), and Winsler et al. (2007).

It should be noted findings of the current work cannot be directly compared to findings in above works, both with consistent and inconsistent results, because private speech is a age related phenomenon and subjects in above research works were mostly preschool children or children up to 6 years old, while age range of subjects in the current research was 10 years and 10 months and above.

According to Vygotesky, language development had three stages. Social speech stage, which appears prior to 3 years old, private speech which appears between 3 to 7 years old, and internal speech which appears after 7 years old. Thus, according to Piaget and Vygotesky, self-driving speech (private speech as termed by Vygotesky) disappears after the year 7 or it changes. However, Piaget considers children speech in pre-operational stage (3-7 years old) as selfdriving and unsocial, while Vygoteskybelieves this speech is effective in self-regulation. Thus, studies which supported main assumptions of Vygotesky were done with subjects in age range 3 to 7 years. Winsler and Naglieri (2003) with a sample of 5 to 17 years old children showed verbal strategies are correlation with competencies of young children and self-talk is not correlated with performance in task in older children. However, current work attempted to investigated usefulness of this type of speech in older ages (above 10 years), not children in 3 to 7 years.

The other important point is that in most research works, instead of private speech, impact of other similar methods was also used. Loud thinking, self-expression, verbal thinking, and cognitive self-learning are among these methods. These methods differ in terms of quality and implementation in most cases with private speech. Cognitive and metacognitive approaches are cases which are used, trained or emphasized in some of these methods. Some of research works showed usefulness of these methods even in higher ages or in college students, it is probably due to the same cognitive and meta-cognitive approaches which were used or learned in these method. Although Vygotesky and some authors considered different functions including cognitive and self-regulation for private speech, the way of using private speech or self-talk or self-explanation is subject to personal differences. However, further works are needed with different methodology.

Thus, findings of the research should be considered give above issues. To this end, it is suggested interested authors conduct similar research works with children in different age groups and other similar methods.

\section{Resources}

Beaudichon J. (1973). Nature and instrumental function of private speech in problem solvingsituations.Merill-Parmer Quarterly, 19,119 135.

Behrend D.A., Rosengren K.S., and Perimutter M. (1989). A new look at children's private speech: the effect of age, task difficulty, and patent parent presence. International Journal of Behavioral Development, 12, 305 - 320.

Berk L.E. (1986). Relationship of elementary school children's private speech to behavioral accompaniment to task, attention, and task performance. Developmental Psychology, 22, 671 - 680.

Berk I. E. (1992). Children's private speech: An over view of theory and the status of research. In R. M. Diaz \& L. E. Berk (Eds). Private speech: from social interaction to self-regulation (pp. 17-53). Hore, UK: Lawrence Erlbaum Associates.

Berk L.E., and Garvin R.A. (1984). Development of private speech among low-income Appalachian children. Developmental Psychology, $20,271-286$.

Berk L.E., and Potts M.K. (1991). Development and functional significant of private speech amoung attention deficit hyperactivity disordered and normal boys. Journal of Abnormal childpsychology, 19, 357 - 377.

Bevens J.A., and Berk L.E. (1990). A longitudinal study of the development of elementary school children's private speech. Merill Palmer Quarterly, 36, 443 - 463.

Duncan R.M., nd Cheyne J.A. (2002). Private speech in young adults :Task difficulty, self-regulation ,and psychological predication. CognitiveDevlepment,16,889-906.

Duncan R., and Pratt M. (1997). Microgeneticchange in the quality and quantity of preschooler' private speech.International Journal of Behavioral Development, 20, 367 - 383.

Fernyhough C., and Fradley E. (2005). Private speech on an executive task: relations with task difficulty and task performance. Cognitive 
Development, 20: 103 - 120.

Frauenglass. M., and Diaz R. (1985). Self- regulatory functions of children's private speech: A critical analysis of recent challenges to Vygotesky's theory. Developmental psychology, 21, 357 - 364.

Goudena P.P. (1987). The social nature of private speech preschoolers during problem solving. International Journal of behavioral Development, 2 (10), 187 - 206.

KohLberg L., Yaeger. J., and Hjertholm E. (1968). Private speech: Four studies and a review of theories. Child Development, 39,691 736.

Kopecky H., Chang H. T., Kloman R., Thatcher J. E., Joan E., and Borgstedt A. D. (2005). Performance and private speech of children with Attention - deficit/ Hyperactivity Disorder while taking the tower of Hanoi Test: Effects of depth of search, diagnostic subtype, and methylphenidate. Journal of Abnormal child psychology, 5 (33), 625 - 638.

Lane S.M., and Schooler J.W. (2004). Skiming the surface verbal over shadowing of analogical retrieval psychological. Science, 15,715 $-715$.

Matuga J.M. (2003). Children's private speech during algorithmic and heuristic drawing tasks. Contemporary Educational psychology, 28 (4), 5520572.

Matuga J.M. (2004). Situated creativity activity: the drawings and private speech of young children. Creativity Research Journal.16 (2 \& 3). 267 - 281.

Roberts R.N., and Tharp R.G. (1980). A naturalistic study of school children's private speech in a academic problem- solving task. Cognitive Therapy and Research. 4 (4), 341 - 352.

Winsler A., De Leon J.R., Wallace B.A., Carlton M.P., and Willson-Quayel A. (2003). Private speech in preschool children: Developmental stability and change, across - task consistency, and relations with classroom behavior. Journal of Child Language, 30, 583 - 608.

Winsler A., Diaz R. M., \& Montero I. (1997). The role of private speech in the transition from collaborative to independent task performance in young children. Early childhood Research quarterly, 12, 59 - 79.

Winsler A., and Naglieri J. A. (2003). Overt and covert verbal problem- solving strategies: Developmental trends in use, awareness, and relation with task performance in children age 5 to 17 . Child Development, 74, 659 - 678.

Winsler A., Manfra L., and Diaz R.M. (2007). Should I let them talk?, private speech and task performance among preschool children with and without behavior problems. Early childhood Research quarterly, 22, 215 - 231. 